\title{
Compliance to guidelines for the prescribing of antibiotics in acute infections at Namibia's national referral hospital: a pilot study and the implications
}

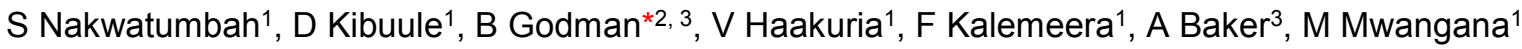 \\ ${ }^{1}$ School of Pharmacy, Faculty of Health Sciences, University of Namibia \\ Emails: sonia.miranda.polo@gmail.com; dkibuule@unam.na; vhaakuria@unam.na; \\ fkalemeera@unam.na; mmubita@unam.na \\ ${ }^{2}$ Department of Laboratory Medicine, Division of Clinical Pharmacology, Karolinska Institutet, \\ Karolinska University Hospital Huddinge, SE-141 86, Stockholm, Sweden. Email: \\ Brian.Godman@ki.se \\ ${ }^{3}$ Strathclyde Institute of Pharmacy and Biomedical Sciences, University of Strathclyde, Glasgow, UK \\ Email: Brian.godman@strath.ac.uk; Amanj.baker@strath.ac.uk
}

\section{Corresponding author*}

Brian Godman, Division of Clinical Pharmacology, Karolinska Institute, Karolinska University Hospital Huddinge, SE-141, Stockholm, Sweden. Email: Brian.Godman@ki.se. Tel: +46858581068, Fax +46859581070 and Strathclyde Institute of Pharmacy and Biomedical Sciences, university of Strathclyde, Glasgow G4 ORE, United Kingdom. Email: brian.godman@strath.ac.uk

\begin{abstract}
Background: Sub-optimal antibiotic prescribing remains a public health concern in Namibia. The objective is to determine the level and predictors of compliance to guidelines in the prescribing of antibiotics in acute infections at a national referral hospital in Namibia to improve future prescribing. Methods: Descriptive observational cross-sectional study. The clinical records of patients receiving care were reviewed. Prescribing practices were assessed using a self- administered questionnaire with reference to Namibia Standard Treatment Guidelines (NSTG). Results: The majority of prescriptions (62\%) complied with the NSTGs; however, lower than national targets (95\%). Most prescriptions were empiric and prescribers typically made reference to the NSTG (58\%). Diagnosed infections were principally respiratory infections $(58 \%)$ and penicillins were the most used antibiotics. Good concurrence between signs and symptoms with the diagnosis; diagnosis of upper respiratory tract, oral-dental and urogenital infections with prescribing of penicillins. Combination antibiotics and amphenicols were independent predictors of compliance to the NSTGs. The main behaviours associated with antibiotic prescribing were patient influences, clinical state, and access to guidelines. Conclusions: Compliance to NSTGs is suboptimal. Prescribing of combination antibiotics, penicillins and diagnosis of oral dental, genitourinary and ear, nose and throat infections were important predictors for NSTG compliance. There is a need to implement antibiotic indicators and stewardship programmes, and ensure access to NSTGs, to improve future antibiotic prescribing in Namibia.
\end{abstract}

\section{Introduction}

Sub-Sahara Africa has the highest burden of infectious disease in the world [1]. The global efforts against HIVIAIDS [2], combined with pushing the WHO essential medicines programmes [3] and other factors including extensive self-purchasing of antibiotics in Africa [3-7], has resulted in the consumption of antibiotics in sub-Saharan Africa tripling in recent years [8-11]. A number of interventions have been implemented to enhance access to medicines and promote appropriate antibiotic prescribing to help reduce antimicrobial resistance (AMR) development [12-14]. This is because AMR is a growing public health challenge across countries including sub-Sahara Africa, increasing morbidity, mortality and costs [15-21].

In Namibia, resistance to essential antimicrobials has been estimated to be between $25-98.9 \%$ $[22,23]$. This is not helped by the excessive prescribing of antibiotics at health facilities in Namibia, estimated at between $28-83 \%$ of all prescriptions [24-26], coupled with increasing recognition that the over use of antibiotics is associated with increasing AMR rates [18, 27-34].

The unnecessary use of antibiotics has been associated mainly with outpatient department (OPD) related illnesses [35], particularly acute upper respiratory infections (URTIs) [6, 34, 36-38] and diarrhoea - related illnesses [39]. The majority of infections in OPD care are acute and of viral origin 
$[31,38,40,41]$, which do not necessitate antibiotics [18,42,43]. Unfortunately, the over use of antibiotics in OPD related illnesses remains common in both the public and private healthcare sectors in Namibia $[24,26.44]$. This is despite the availability of Namibian Standard Treatment Guidelines (NSTG) in public health facilities since 2012 [26,45]. However, efforts at improving the quality health care in Namibia have generally been sub-optimal $[46,47]$.

The quality of antibiotic prescribing in outpatients or ambulatory care across countries has been compromised by high workloads [48], short consultation times [49], high turnover of staff and with most staff lacking experience and qualifications $[50,51]$. Several Health Management Information System (HMIS) reports and medicine use surveys in Namibia have shown sub-threshold levels of the Health Facility indicator 13 (HF-13 indicator), which measures the percentage of prescriptions with an antibiotic [52]. However, the impact of the introduction on the HF-13 indicator has not been evaluated to date. There has also been limited local guidance on potential interventions to improve future antibiotic prescribing in OPDs to complement the Namibian STGs, although this is changing [14,53]. In addition, antibiotic use policies in Namibia are currently not comprehensive. As a result, there is a need to better explore potential predictors for antibiotic use in OPDs in Namibia, and tailor policies to address areas of concern. This is because the impact of any interventions, including the availability of the Namibian STGs [45] and antimicrobial stewardship programmes [54], remains unknown.

Consequently, we sought to determine the rate and predictors of antibiotic prescribing in OPD care in Namibia, as well as assessing antibiotic prescribing compliance against the current recommendations in the NSTGs. Subsequently, use the findings to develop pertinent policies to improve future antibiotic use in Namibia. We also believe our findings will have potential implications for other sub-Saharan countries as they monitor and refine their antibiotic use.

\section{Methods}

\section{Study design and setting}

An analytical cross-sectional survey design, adapted from the WHO medicine use survey, was undertaken [55]. Both quantitative and qualitative data on antibiotic prescribing were collected from patient prescription records and prescribing cadres at the outpatient department of Katutura Intermediate Hospital. This is a national referral and teaching hospital located in Windhoek, which is the capital of Namibia. It has 12 OPD consultation rooms and each doctor sees an approximate of 50100 patients a day. Consequently this study can provide a realistic scenario of current prescribing patterns in OPDs in Namibia.

\section{Study subjects}

The study assessed antibiotic prescribing based on an analysis of prescription records and interviews of prescribers. The outpatient department's prescription turnover was estimated at 18,790 prescriptions per quarter. There were a total of 97 prescribers at the hospital. These include 13 specialists, 51 medical officers and 33 Intern medical doctors. Consequently, a sample size of 347 prescriptions and 77 prescribers was determined using Epilnfo ${ }^{\mathrm{TM}}$ version 7.2 software (CDC, Atlanta, GA, USA), at $95 \%$ confidence level, $80 \%$ power and expected frequency of compliance to NSTGs at $63.3 \%$ [24] for prescriptions and $50 \%$ for prescribers, and a precision of $\pm 5 \%$. The study only included prescribers working in the OPD units and prescriptions that had antibiotic orders after consultations. Prescriptions without a diagnosis or with multiple diagnoses $(>1)$ were excluded from this study since it would be difficult in these circumstances to allocate a medicine to a diagnosis, and assess whether the prescription complies with the NSTG. The prescriptions of patients who did not give consent for review of their health passports, or had a severe illness and were being referred to an inpatient department for further care, were also excluded. Overall, 316 prescriptions were subsequently analysed (Figure 1). 


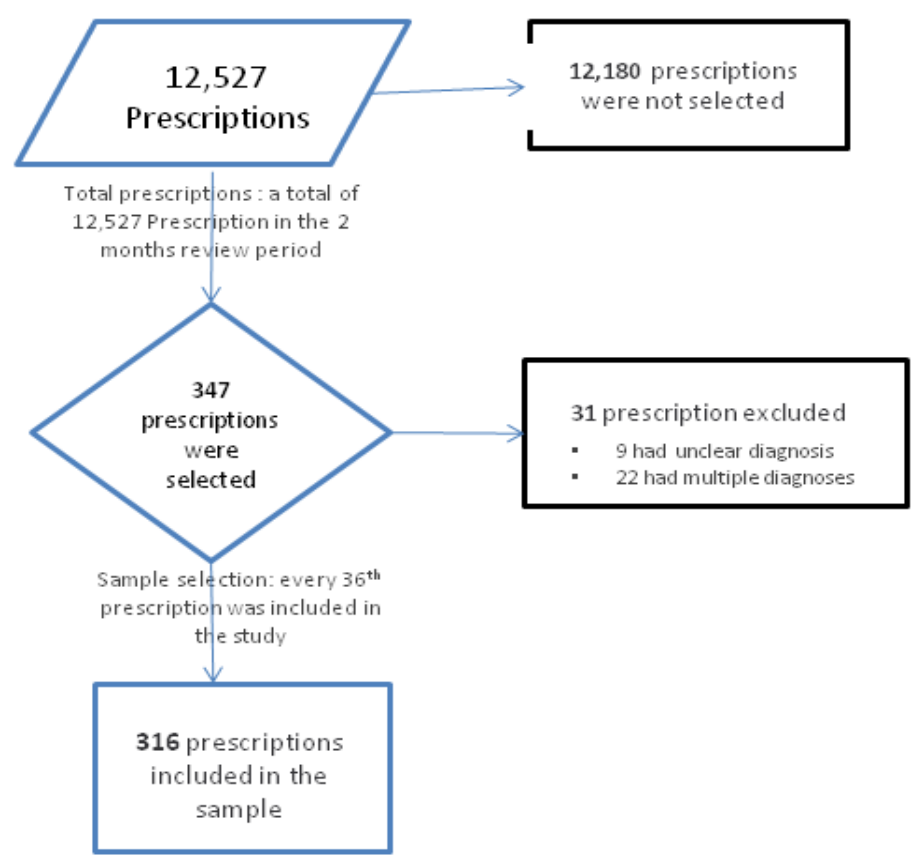

\section{Procedure}

Data were collected by the research team over a two month period from 29th June to 29th August 2016. June to August is winter in Namibia and the OPD generally receives more patients during this time than for other months of the year. In addition in winter, relatively more patients present to the hospital with respiratory tract infections, and there is a corresponding high consumption of antibiotics as revealed by pharmacy records. Consequently, this period was chosen for the study since in appropriate prescriptions for antibiotics are most likely during this period.

The study was undertaken in two stages. The first phase was the quantitative prescription analysis to determine the level and predictors of compliance to NSTG. The second phase was a qualitative assessment using prescriber interviews to describe behaviors behind the prescribing of antibiotics in acute infections. A pre-tested and standardized data abstraction tool was used to collect data from the prescriptions. An interviewer- administered questionnaire was used to assess behaviours and practices towards compliance to STGs when physicians prescribe antibiotics. The prescriptions were selected using a systematic sampling method such that the prescription of every $36^{\text {th }}$ eligible patient was reviewed. The prescribers were selected using a simple random sampling technique. Data on antibiotic prescribing, compliance to STGs, and patient details (demographics, diagnosis) were collected. The compliance to guidelines was determined using a correctness score sheet from a panel assessment of three expert groups - a clinical pharmacist, a consultant physician and the research team.

\section{Criteria for assessing antibiotic prescribing}

The main outcome of the study was the level of compliance to the NSTGs in antibiotic prescribing in ambulatory / OPD care. The patterns of antibiotic prescribing were determined by the type of antibiotic prescribed according to the WHO ATC/DDD classification [56] and the indication of the antibiotic as recommended by the Namibia STG [45]. According to the NSTG, indications for antibiotic use are categorized as: respiratory; gastrointestinal; ear, nose and throat (ENT); genitourinary and obstetrics and gynaecology (OBGY). In addition, whether the prescribed antibiotic was included in Namibia's Essential Medicine List (Nemlist). Other parameters explored included patient socio-demographics, clinical and treatment characteristics. 


\section{Analysis}

Data were entered into Epidata v 3.1 for management and was exported to SPSS Version 23 for quantitative analysis. The World Health Organisation/ International Network for Rational Use of Drugs (WHO/INRUD) [57] prescribing indicators were determined using descriptive statistics. The association of the prescribing indicators and the compliance level were determined using the Chisquared test for categorical variables, student's T-test and/or ANOVA for continuous variables, with the level of significance ( $\alpha$ ) set at $p=0.05$ and a 95\% confidence interval. Cramer's V statistic was used to test the practical significance of this association (with Cramer's $V \geq 0.5$ defined as practical significance). A binary logistic regression model was constructed to determine the coefficients (OR) of the covariates as independent predictors of compliance to STGs in antibiotic prescribing.

\section{Ethics}

Formal ethical approval was granted by the ethics committee at the Ministry of Health and Social services (MoHSS). Permission to conduct the study was given by the hospital management. Confidentiality and anonymity of patients and prescribers was maintained. Specific personal identifiers such as the names of the patients and prescribers were not collected but rather coded identity numbers were assigned to individual study participants.

\section{Results}

A total of 316 (100\% response) outpatient prescriptions were assessed (Figure 1). All the prescriptions were initiated by medical officers (physicians), the majority of which were by female $192 / 316(60.8 \%)$ (Table 1$)$. The majority of patients were female and adult, i.e. $\geq 16$ years. The most diagnosed infections were respiratory tract $(n=185,58.5 \% ; p<0.001)$, urogenital $(n=45,14.2 \%)$ or oral dental infections ( $n=39,12.3 \%$ ) (Table 1). In the majority of prescriptions, the diagnoses indicated were consistent with the clinical presentations $(p<0.001)$; or patients were physical examined $(p$ $<0.001)$ with typically no laboratory investigations $(p<0.001)$.

Table 1: Bivariate analysis of compliance to NSTG in antibiotic prescribing $(n=316)$

\begin{tabular}{|c|c|c|c|c|c|}
\hline \multirow[t]{2}{*}{ Infection } & \multirow[t]{2}{*}{ Total } & \multicolumn{2}{|c|}{ Compliance to NSTG } & \multirow[t]{2}{*}{ OR $(95 \% \mathrm{Cl})$} & \multirow[t]{2}{*}{$p$-value } \\
\hline & & Yes (\%) & No (\%) & & \\
\hline \multicolumn{6}{|l|}{ Patient's Gender } \\
\hline Male & 145 & $96(66.2)$ & $49(33.8)$ & $0.7(0.5,1.1)$ & 0.158 \\
\hline Female & 171 & $100(58.5)$ & $71(41.5)$ & & \\
\hline \multicolumn{6}{|l|}{ Patient's Age } \\
\hline Child (< 16 years) & 149 & 102(68.5) & $47(31.5)$ & $0.6(0.4,0.9)$ & $0.026^{*}$ \\
\hline Adult ( $\geq 16$ years) & 167 & $94(56.3)$ & $73(43.7)$ & & \\
\hline \multicolumn{6}{|l|}{ Prescribing Doctor } \\
\hline Male & 124 & $72(58.1)$ & $52(41.9)$ & $1.3(0.8,2.1)$ & 0.244 \\
\hline Female & 192 & $124(64.6)$ & $68(35.4)$ & & \\
\hline \multicolumn{6}{|l|}{ Presentation \& diagnosis } \\
\hline Consistent & 292 & $189(64.3)$ & $105(35.7)$ & $0.3(0.1,0.7)$ & $0.002^{*}$ \\
\hline Inconsistent & 22 & $7(31.8)$ & $15(68.2)$ & & \\
\hline \multicolumn{6}{|l|}{ Physical Examination } \\
\hline Done & 264 & $170(64.4)$ & $94(35.6)$ & $0.6(0.3,1.0)$ & 0.051 \\
\hline Not done & 52 & $26(50)$ & $26(50)$ & & \\
\hline \multicolumn{6}{|l|}{ Laboratory investigation } \\
\hline Done & 40 & $25(62.5)$ & $15(37.5)$ & $1.0(0.5,1.9)$ & 0.947 \\
\hline Not done & 276 & $171(62)$ & $105(38.0)$ & & \\
\hline \multicolumn{6}{|l|}{ Diagnosis (body system) } \\
\hline Gastrointestinal & 20 & $13(65)$ & $7(25)$ & & $0.000^{*}$ \\
\hline Dermatological & 14 & $4(77.8)$ & $18(22.2)$ & & \\
\hline Lower respiratory & 118 & $81(68.6)$ & $37(37)$ & & \\
\hline Obstetric/gynaecological & 5 & $5(100)$ & - & & \\
\hline
\end{tabular}




\begin{tabular}{|c|c|c|c|c|}
\hline HEENT ${ }^{\ddagger}$ & 67 & $46(68.7)$ & $21(31.3)$ & \\
\hline Oral and Dental & 39 & $12(30.8)$ & $27(69.2)$ & \\
\hline Urogenital & 45 & $23(51.1)$ & $22(48.9)$ & \\
\hline Ophthalmological & 4 & $2(50)$ & $2(50)$ & \\
\hline \multicolumn{5}{|l|}{ ATC Class of antibiotic } \\
\hline J01B (Amphenicols) & 2 & $1(50)$ & $1(50)$ & $0.000^{*}$ \\
\hline J01C (Penicillins) & 179 & $136(76)$ & $43(24)$ & \\
\hline J01D (Other $\beta$-lactams) & 43 & $2(4.7)$ & $41(95.3)$ & \\
\hline J01E (Sulphonamides) & 8 & $1(12.5)$ & $7(87.5)$ & \\
\hline J01F (macrolides) & 16 & $12(75)$ & $4(25)$ & \\
\hline J01M (Quinolones) & 12 & $4(33.3)$ & $8(67.7)$ & \\
\hline J01X (other antibiotics) & 12 & $8(67.7)$ & $4(33.3)$ & \\
\hline J01R (combination) & 44 & $32(72.7)$ & $12(27.3)$ & \\
\hline
\end{tabular}

$N B:{ }^{*}=(p<0.05)$-Statistically significant- Pearson Chi-square Test; ${ }^{\ddagger} \mathrm{HEENT}=\mathrm{Head}$, Ear, Eye, Nose and Throat infections

\section{Antibiotic prescribing patterns and behaviour}

Out of the 316 prescriptions, $13(46.4 \%)$ antibiotics were contained in the Namibia's essential medicine list (Nemlist). Eight out of the10 ATC classes containing antibiotics were prescribed. The majority of the prescriptions had one antibiotic $(n=272,86.1 \% ; p<0.001)$ compared to a combination of antibiotics $(n=44,13.9 \%)$. The most prescribed ATC classes of antibiotics were AJ01C (Penicillins), AJ01D (other $\beta$-lactams antibacterials) and AJ01R (combination antibiotics) (Figure 2).

Figure 2: Patterns of antibiotic prescribing by ATC Class and STG indication

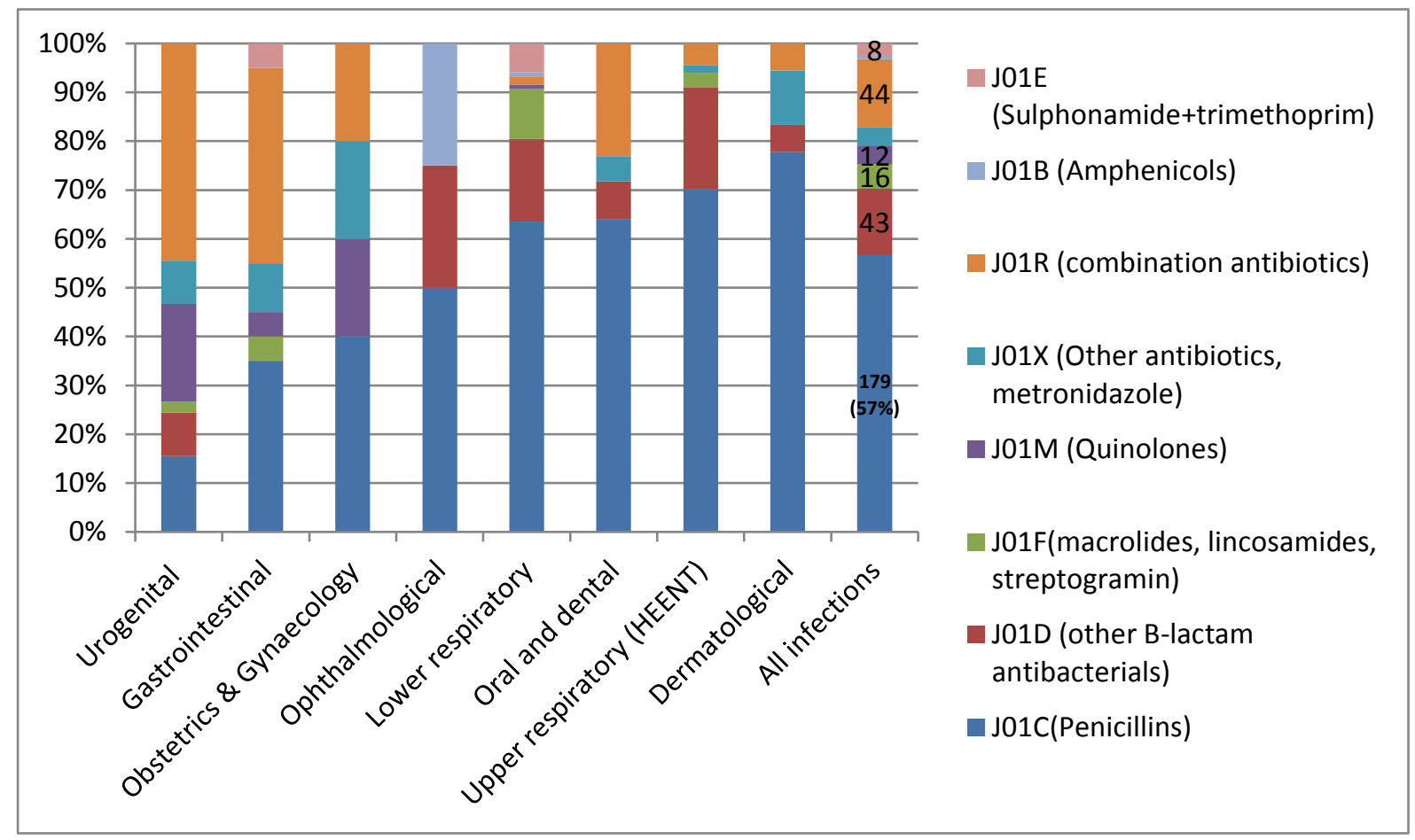

The majority of the antibiotics were prescribed after physical examination but with no laboratory investigations (Table 1). The most prescribed combinations of antibiotics were metronidazole and amoxicillin.

Out of the 77 prescribers interviewed, the majority $(71 \%)$ had less than 5 years work experience and attended to between 1 to 50 patients per day $(65 \%)$. More than half of the prescribers $(46-60 \%)$ self- 
reported that they referred to the NSTG in their antibiotic prescribing. The majority of whom, i.e. 33/46 $(72 \%)$, used the NSTG on a regular basis (every week). Limited access to copies of an up-to-date NSTG (64\%) was the main reason why prescriber's did not regularly use the guidelines in their prescribing of antibiotics.

Overall, the main thematic areas driving antibiotic prescribing were patients' influence, access to upto-date objective information, severity/complexity of the patients' condition and the availability of antibiotics in the hospital (Table 2).

Table 2: Qualitative findings on prescribing behaviours in antibiotic prescribing

\begin{tabular}{ll}
\hline Thematic area & Sub-thematic areas for antibiotic prescribing behaviours \\
\hline Patient pressure & $\begin{array}{l}\text { Prescribers cited influence by patients to prescribe antibiotics. } \\
\text { "sometimes patients request for antibiotics they are used to" (85\%). } \\
\text { "Patient expects to be treated with antibiotic when they visit us" (73\%). }\end{array}$ \\
Access to up-to-date & $\begin{array}{l}\text { Prescribers did not have access to up-to-date objective guidelines for } \\
\text { prescribing antibiotics. "Lack of evidence" - 44\%, "we use our past } \\
\text { experiences to prescribe the most effective antibiotic" (47\%) }\end{array}$ \\
Patients condition & $\begin{array}{l}\text { Prescribers self-reported that the severity or the patient's condition } \\
\text { determined whether empiric antibiotic therapy was initiated. "A } \\
\text { complex case or clinical condition would necessitate antibiotic } \\
\text { therapy" (76\%); "sometimes the diagnosis is unclear and the patient's } \\
\text { life is unclear"-(54\%). Prescribers reported initiating antibiotic therapy } \\
\text { only when they were certain of diagnosis (55\%). Majority reported that } \\
\text { they prescribed antibiotics empirically (60\%) based on signs and } \\
\text { symptoms, after laboratory investigations }(67 \%) \text { or after performing a } \\
\text { physical examination (71\%) }\end{array}$ \\
The unavailability of antibiotics (58\%) indicated in the guidelines \\
prompted prescribers to use alternative antibiotics that were in stock. \\
These might not have been the antibiotics of choice.
\end{tabular}

\section{Compliance to guidelines in antibiotic prescribing}

Most of the antibiotic prescriptions, i.e. 62\% (196/316), complied with Namibian STGs. Compliance to the NSTG ranged from $31 \%$ to $100 \%$ by type of infection (Figure 2 ). The compliance to antibiotic prescribing was optimal $(\geq 80 \%)$ for obstetric and gynecological infections $(100 \%)$, with compliance sub-optimal in 8 out of $9(88.9 \%)$ of the NSTG indications, particularly oral dental, ophthalmological, urogenital infections and respiratory infections (Figure 3 ).

Bivariate analysis in Table 1 showed a significant association between compliance to NSTGs with the patients' age category $(p=0.026)$, type of infection $(p<0.001)$, consistency between signs and symptoms and the diagnosis $(p<0.002)$, and the ATC antibiotic category $(p<0.001)$ (Table 1$)$. 
Figure 3: Compliance to NSTG in antibiotic prescribing

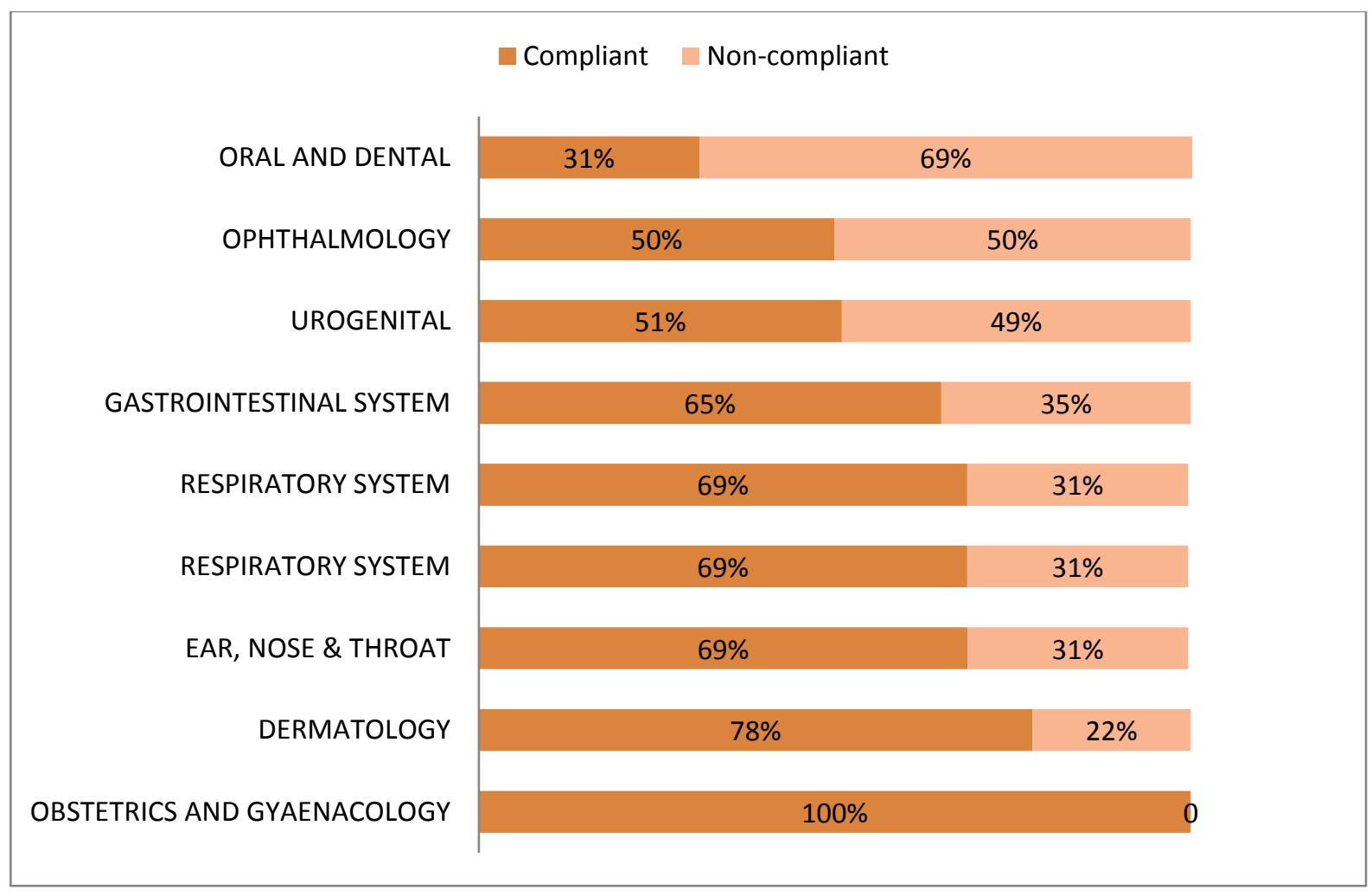

\section{Multivariate logistic model for factors associated with compliance to NSTG prescribing} A logistic regression analysis was conducted to predict the compliance to NSTG prescribing for the 316 patients initiated on antibiotics, based on the patient's demographics, diagnosis, ATC class antibiotic and assessment of the patient (Table 3). A test of the full model against a constant only model was statistically significant, indicating that the predictors as a set reliably distinguished between compliance and non-compliance to NSTGs when prescribing $\left(\chi^{2}=162.6, p<0.001\right.$ with $\left.d f=20\right)$. Nagelkerke's $R^{2}$ of 0.547 indicated a good relationship between prediction and grouping by compliance to NSTG.

Prediction success overall was $84.8 \%$ (92.2\% for compliance to NSTG and $72.5 \%$ for non-compliance to STG prescribing). The Wald criterion demonstrated consistency between the signs and symptoms $(\mathrm{OR}=5.2,95 \% \mathrm{Cl}: 1.4,19.2)$ ), diagnosis of dental or oral infections (OR=0.1,95\% $\mathrm{Cl}: 0.03,0.3)$, urogenital infections $(\mathrm{OR}=0.3,95 \% \mathrm{Cl}: 0.1,0.9)$, and the ATC class of the prescribed antibiotic, including combination antibiotics $(\mathrm{OR}=0.1,95 \% \mathrm{Cl}: 0.03,0.3)$ and $/$ or J01B antibiotics $(\mathrm{OR}=0.3$, $95 \% \mathrm{Cl}: 0.1,0.9$ ), which all made a significant contribution to predictions. On the other hand, patients' demographics, category of prescriber, diagnosis and health facility level were not significant predictors for compliance to NSTGs. The covariates of dental or oral infections, urogenital infections, the prescribing of combination antibiotics, and/ or J01B antibiotics were identified as independent risk factors for compliance to NSTG prescribing (Table 3). 
Table 3: Multivariate analysis of compliance to NSTG in antibiotic prescribing

\begin{tabular}{|c|c|c|}
\hline Covariate & OR $(95 \% \mathrm{Cl})$ & $p$-value \\
\hline \multicolumn{3}{|l|}{ Patient's Gender } \\
\hline Male & $1.8(0.9,3.5)$ & 0.078 \\
\hline Female & 1 & \\
\hline \multicolumn{3}{|l|}{ Patient's Age } \\
\hline Child (< 16 years) & $2.0(0.8,4.4)$ & 0.134 \\
\hline Adult ( $\geq 16$ years) & 1 & \\
\hline \multicolumn{3}{|l|}{ Prescribing Doctor } \\
\hline Male & $0.6(0.3,1.2)$ & 0.185 \\
\hline Female & 1 & \\
\hline \multicolumn{3}{|l|}{ Presentation \& diagnosis } \\
\hline Consistent & $5.2(1.4,19.2)$ & $0.014^{*}$ \\
\hline Inconsistent & 1 & \\
\hline \multicolumn{3}{|l|}{ Physical Examination } \\
\hline Done & $2.3(0.9,5.5)$ & 0.067 \\
\hline Not done & 1 & \\
\hline \multicolumn{3}{|l|}{ Laboratory investigation } \\
\hline Done & $1.2(0.5,3.5)$ & 0.672 \\
\hline Not done & 1 & \\
\hline Diagnosis (body system) & & $0.001^{*}$ \\
\hline Upper respiratory(ENT) & 1 & \\
\hline Gastrointestinal & $0.4(0.1,1.5)$ & 0.155 \\
\hline Dermatological & $0.8(0.1,4.6)$ & 0.778 \\
\hline Lower respiratory & $1.4(0.5,3.7)$ & 0.528 \\
\hline Obstetric/gynaecological & 3061526198 & 0.999 \\
\hline Oral and Dental & $0.1(0.03,0.3)$ & $0.000^{*}$ \\
\hline Urogenital & $0.3(0.1,0.9)$ & $0.045^{*}$ \\
\hline Ophthalmological & $0.4(0.02,7.2)$ & 0.503 \\
\hline ATC Class of antibiotic & & $0.000^{*}$ \\
\hline J01C (Penicillins) & 1 & \\
\hline J01B (Amphenicols) & $0.3(0.1,0.9)$ & $0.049^{*}$ \\
\hline J01D (Other $\beta$-lactams) & $0.4(0.1,1.7)$ & 0.221 \\
\hline J01E (Sulphonamides) & $0.8(0.04,17.1)$ & 0.891 \\
\hline J01F (Macrolides) & $1.1(0.2,5.1)$ & 0.943 \\
\hline J01M (Quinolones) & $1.6(0.6,5.5)$ & 0.351 \\
\hline J01X (Other antibiotics) & $1.8(0.4,8.1)$ & 0.457 \\
\hline J01R (Combination) & $0.1(0.03,0.3)$ & $0.000^{*}$ \\
\hline Constant & 0.226 & 0.336 \\
\hline
\end{tabular}

${ }^{*}=(p<0.05)$-Statistically significant- Pearson Chi-square Test; ENT= Ear Nose and Throat

\section{Discussion}

In this study, a considerable proportion of antibiotic prescriptions were for patients $<16$ years of age. This is a concern as this age group currently accounts for $36 \%$ of Namibia's population, and has been reported at high risk for acute infections [58]. In addition, acute lower respiratory and head, ear, eye, nose and throat (HEENT) infections accounted for more than half of the diagnoses (Table 1).

Appropriate prescribing of antibiotics in acute respiratory infections is particularly important as the vast majority of URTIs are viral in origin $[14,18,31,38,40,41,43]$, although lower respiratory tract infections are the third leading cause of mortality worldwide [59.60]. 
Though not a significant predictor for compliance to NSTGs, the majority of the antibiotic prescriptions were generated after physical examination, although approximately 9 out of 10 patients did not undergo laboratory investigations (Table 1). In this study, the number of patients who did not undergo physical examination could be explained by the busy consultations in the OPD. The limited number of laboratory investigations undertaken suggests that empiric prescribing of antibiotics is still a common practice in ambulatory care $[26,61]$. This may be partly due to a lack of a rapid diagnostic testing for antibiotic sensitivity, lack of policies for antibiotic prescribing and/or the lack of capacity to perform investigations on every patient. This practice may aggravate unnecessary antibiotic use and increase AMR rates unless there is strict adherence to current guideline policies.

In this study, compliance of antibiotic prescribing with the recommendations of the NSTG was found to be sub-optimal $(62 \%)$ compared with MoHSS and global targets of $>95 \%[52,62]$. This lower level of compliance could be due to a lack of formal monitoring systems as well as a lack of outpatient antimicrobial stewardship programmes. In addition, a lack of readily available NSTGs to guide prescribing. A systematic review on antimicrobial stewardship programmes suggests that certain interventions such as prescriber/and patient education, guideline implementation, delayed prescribing, decision support systems and laboratory testing, can reduce unnecessary antimicrobial overuse $[14,54]$. Evidence from Bangladesh suggests that the roll-out of STGs without undertaking antimicrobial stewardship interventions will typically not significantly reduce antibiotic prescribing [63].

Similar studies in the private and public sector in Namibia have also reported sub-optimal levels of compliance to guidelines, and demonstrated that the preferred choices of antibiotics were not in line with the NSTGs $[24,26]$. In Namibia's private sector, non-compliance has been associated with the prescribing of second-line antibiotics in place of the first-line choices according to the NSTGs. This is partly because of the limited roll out and use of the NSTGs among private health facilities in Namibia. This calls for a pragmatic approach towards a public/ private sector mix in reducing unnecessary antibiotic use. Such strategies should include a common antibiogram and antibiotic treatment guidelines as well as a monitoring and reporting systems to measure future antibiotic use.

In this study (Figure 2), over half of the prescriptions had antibiotics belonging to J01C (penicillins), and these were prescribed mainly for respiratory and/or gastrointestinal infections. Several studies in the sub-Saharan region have reported a wide use of these antibiotics partly due to a lack of comprehensive guidelines advocating different approaches [64]. Secondly, according to studies conducted in Lesotho [61], Namibia [44] and Uganda [6], respiratory tract infections are the most common infections in outpatient departments for which J01C antibiotics are the most prescribed. These studies have also reported high prevalence of acute respiratory infections (ARIs) in OPD units, ranging between $30-70 \%$. It is important to note, as mentioned, that this study was conducted in winter (May - August), the peak period for ARIs in Namibia, which may have resulted in a higher incidence of ARIs and antibiotic prescribing in this study.

Similar studies in Namibia's public [44] and private [26] sectors have also reported the over use of J01C antibiotics - including amoxicillin with clavulanic acid (co-amoxiclav $\left.{ }^{\circledR}\right)$, amoxicillin as well as ciprofloxacin. This is mainly due to treatment policies and guidelines recommending the use of $\mathrm{J} 01 \mathrm{C}$ antibiotics as first line antibiotics for most acute in infections including respiratory, gastrointestinal and genitourinary and musculoskeletal infections [64]. Whilst Pereko and colleagues reported that most isolated bacterial pathogens had high sensitivity to amoxicillin, the overuse of these penicillins for ARIs has been associated with resistance in the public sector, and poses a potential selective pressure on this class of medicines $[22,23,26,36,64]$.

The bivariate analysis showed a statistically significant association between the number of infections and compliance to NSTG recommendations. These include respiratory $(p=0.016)$, oral and dental infections $(p<0.001)$ as well as urogenital $(p=0.022)$ infections (Table 1$)$. Kunda also found a significant association between the type of infections and the rate of antibiotic prescribing $(p<0.001)$ [44]. Consequently, by focusing on key infections with currently poor compliance to NSTGs, and instigating interventions to reduce inappropriate antibiotic prescribing especially where viral infections are suspected, there is the potential to appreciable improve antibiotic use. This will be the subject of further research. 
A multivariate logistic model identified the concurrence between signs and symptoms with the diagnosis, type of infection (diagnosis) particularly upper respiratory, oral dental and genital urinary infections, as well as the choice of antibiotic including J01C (penicillins), J01R(combination antibiotics) and J01B(Amphenicols), as independent predictors of compliance to NSTGs with respect to antibiotic prescribing (Table 3). Consequently, future interventions to improve antibiotic prescribing should incorporate indicators for assessing these covariates. This will again be the subject of future research in Namibia as part of developing pertinent quality indicators for antibiotic prescribing rather than continually assessing prescribing against a single number for all prescriptions currently advocated by the WHO and others [57]. The findings may also be of interest to other countries with similar characteristics to Namibia.

Qualitative assessments regarding antibiotic prescribing behaviours among physicians showed that, patients' request for antibiotics (85\%), and their expectation to be prescribed an antibiotic (73\%), were important drivers of unnecessary antibiotic prescribing. Similar findings have been found in other studies [18]. This demonstrates the need for patient and prescriber education, along with measures to enhance appropriate antibiotic prescribing, as a key component of any antimicrobial stewardship programme [54] along with interventions to enhance adherence to NSTGs. This has worked successfully in other countries [65-67].

\section{Conclusion and recommendations}

The study demonstrated sub-optimal compliance to NSTG regarding antibiotic prescribing in OPDs in Namibia. There was also an overuse of J01C antibiotics for the management of acute infections. The respiratory, urogenital and oral dental infections, as well the prescribing of J01C (Penicilins), J01B (Amphenicols) and J01C (combination antibiotics), appear important predictors of compliance. In view of this, tailored antimicrobial stewardship programmes involving a multidisciplinary approach should be instituted in Namibia, building on successful programmes in other countries. This includes ready availability of NSTGs in OPDs given current limited access in some settings.

Specific indicators on the type of infection and choice of antibiotic regimen should also be developed and validated for improving antibiotic prescribing in ambulatory care in the future. There is also a need to undertake this research in other settings in Namibia. These are activities for the future.

\section{Limitations}

We accept that the study adopted a cross-sectional design and patients were not followed up to determine the treatment outcomes. We also excluded patients with more than one diagnosis. In addition, only patients with acute infections were included in this study. We also only conducted the research in one major centre. Furthermore, we acknowledge we only conducted in winter. However, relatively more patients present to hospitals with RTIs at this time in Namibia. Consequently, we believed an assessment of the appropriateness of antibiotic prescribing during winter, given greater pressures on OPDs at this time, would give a good indication of the current quality of antibiotic prescribing. We are also aware that we were unable to compare prescribing practices among different physician types as the prescription forms used made no provision for the doctor's designation. We acknowledge that further studies are warranted to explore antibiotic prescribing in more detail given current concerns. We also are aware that we need to track the extent of self-purchasing of antibiotics in community pharmacies in Namibia as this can be extensive in some African countries. Despite these limitations, we believe our findings are robust and already provide guidance to the authorities in Namibia on potential future strategies to consider and potentially adopt to improve the prescribing of antibiotics throughout Namibia.

\section{Key Points}

- Indiscriminate prescribing and dispensing of antibiotics is the principal cause of AMR worldwide. Currently, there is limited evidence of compliance with national STGs in Namibia (NSTGs), which needs to be addressed to reduce future AMR rates

- There are also concerns that crude antibiotic prescribing targets established by the WHO and others may not truly reflect appropriate prescribing and that adherence to standard guidelines such as NSTG may be a better indicator of prescribing quality 
- The most common diagnosis in OPDs in Namibia was respiratory infections, typically prescribed a penicillin. Encouragingly $62 \%$ of prescriptions adhered to NSTGs; however, this is below the national $95 \%$ target

- There was concurrence between signs and symptoms with the diagnosis, diagnosis of a URTI, oral-dental or genital urogenital infection as predictors of compliance to NSTGs; the prescribing of penicillins, combination antibiotics and amphenicols were independent predictors of compliance to NSTGs with respect to the prescribing of antibiotics in acute infections

- The main behaviours associated with antibiotic prescribing were patient influences, the clinical state of the patient's condition as well as access to up-to-date objective guidelines and essential antibiotics

- There is need to implement a formal antibiotic indicator monitoring system in Namibia as well as antimicrobial stewardship programmes and continuous professional development to improve future antibiotic use. This could include new quality indicators given concerns with current ones

\section{Conflict of interest and funding}

The authors hereby declare that they have no conflicts of interest to disclose. This study did not receive any specific grant from any funding agency in the public, commercial or not-for-profit sectors.

\section{Acknowledgements}

The authors wish to acknowledge the assistance rendered by the staff at the outpatient departments of Katutura State hospital, Ministry of Health and Social Services in collection of the data.

\section{Author contributions}

SN, DK, VK and MM conceptualized and developed the research, implemented the research and performed data analysis. AB, FK and BG helped with the statistical analysis, edited and appraised the paper during the various stages of publication. All authors permitted the submission of this paper to this journal.

\section{References}

1. Wanyiri JW, Kanyi $H$, Maina $S$, Wang DE, Ngugi $P$, O'Connor $R$ Infectious diarrhoea in antiretroviral therapy-naive HIVIAIDS patients in Kenya. Trans R Soc Trop Med Hyg. 2013;107(10):631-8

2. Avdeeva O, Lazarus JV, Aziz MA, Atun R. The Global Fund's resource allocation decisions for HIV programmes: Addressing those in need. J Int AIDS Soc. 2011 Oct 26;14:51

3. Laing R, Waning B, Gray A, Ford N, 't Hoen E. 25 years of the WHO essential medicines lists: progress and challenges. Lancet. 2003;361(9370):1723-9

4. Donkor ES, Tetteh-Quarcoo PB, Nartey P, Agyeman IO. Self-medication practices with antibiotics among tertiary level students in Accra, Ghana: A cross-sectional study. Int J Environ Res Public Health. 2012;9(10):3519-29

5. Kalungia AC, Burger J, Godman B, Costa JO, Simuwelu C. Non-prescription sale and dispensing of antibiotics in community pharmacies in Zambia. Expert Rev Anti Infect Ther. 2016;14(12):1215-1223

6. Kibuule D, Kagoya HR, Godman B. Antibiotic use in acute respiratory infections in under-fives in Uganda: findings and implications. Expert Rev Anti Infect Ther. 2016;14(9):863-72.

7. Morgan DJ, Okeke IN, Laxminarayan R, Perencevich EN, Weisenberg S. Non-prescription antimicrobial use worldwide: A systematic review. Lancet Infect Dis. 2011;11(9):692-701

8. Center for Disease Dynamics, Economics \& Policy. 2015.State of the World's Antibiotics, 2015. CDDEP: Washington, D.C. Available at URL: https://cddep.org/sites/default/files/swa_2015_final.pdf 9. Heather F, Versporten A, Whitelaw A, Goossens H, Taljaard J.

The Global Point Prevalence Survey of Antimicrobial Consumption and Resistance (Global-PPS): Results of antimicrobial prescribing in a South African Tertiary Hospital. Available at URL:

http://www.global-pps.com/wp-content/uploads/ECCMID-2016_South-Africa.pdf

10. Reardon S. Dramatic rise seen in antibiotic use. Available at URL: https://doi.org/10.1038/nature.2015.18383

11. Van Boeckel TP, Gandra $S^{2}$, Ashok $A^{2}$, Caudron $Q^{1}$, Grenfell $B T^{3}$, Levin SA et al.Global antibiotic consumption 2000 to 2010: An analysis of national pharmaceutical sales data. Lancet Infect Dis. 2014;14(8):742-50.

12. Massele A, Burger J, Katende-Kyenda NL, Kalemeera F, Kenaope $T^{5}$, Kibuule D et al. Outcome of the first Medicines Utilization Research in Africa group meeting to promote sustainable and rational medicine use in Africa. Expert Rev Pharmacoecon Outcomes Res. 2015;15(6):885-8. 
13. Marseille E, Hofmann PB, Kahn JG. HIV prevention before HAART in sub-Saharan Africa. Lancet. 2002;359(9320):1851-6

14. Dyar OJ, Beovic B, Vlahovic-Palcevski V, Verheij T, Pulcini C. How can we improve antibiotic prescribing in primary care? Expert review of anti-infective therapy. 2016;14(4):403-13

15. de-Graft Aikins A, Unwin N, Agyemang C, Allotey P, Campbell C, Arhinful D. Tackling Africa's chronic disease burden: from the local to the global. Global Health. 2010;6:5

16. HM Government. Antimicrobial Resistance : Tackling a crisis for the health and wealth of nations.

Available via UR: https://amr-review.org/sites/default/files/AMR\%20Review\%20Paper\%20-

\%20Tackling\%20a\%20crisis\%20for\%20the\%20health\%20and\%20wealth\%20of\%20nations_1.pdf

17. Kimang'a AN. A situational analysis of antimicrobial drug resistance in Africa: are we losing the

battle? Ethiopian Journal of Health Sciences 2012; 22(2):135-143. https://doi.org/10.4314/ejhs.v22i2.

18. Md Rezal RS, Hassali MA, Alrasheedy AA, Saleem F, Md Yusof FA, Godman B. Physicians'

knowledge, perceptions and behaviour towards antibiotic prescribing: a systematic review of the

literature. Expert review of anti-infective therapy. 2015;13(5):665-80

19. Shallcross LJ, Davies SC. The World Health Assembly resolution on antimicrobial resistance. J

Antimicrob Chemother. 2014;69(11):2883-5

20. World Health Organization. Antimicrobial Resistance: Global report on Surveillance. Available at URL: http://apps.who.int/iris/bitstream/10665/112642/1/9789241564748_eng.pdf?ua=1

21. World Health Organization. Worldwide country situation analysis: response to antimicrobial resistance. Available from URL: http://www.who.int/drugresistance/documents/situationanalysis/en/

22. lileka AEK, Mukesi M, Engelbrecht F, Moyo SR. Antimicrobial Susceptibility Patterns of

Staphylococcus aureus Strains Isolated at the Namibia Institute of Pathology from 2012 to 2014.

Open Journal of Medical Microbiology, 2016, 6, 116-124

23. Mengistu A, Gaeseb J, Uaaka G, Ndjavera C, Kambyambya K, Indongo L et al. Antimicrobial sensitivity patterns of cerebrospinal fluid (CSF) isolates in Namibia: implications for empirical antibiotic treatment of meningitis. J Pharm Policy Pract. 2013 Jun 13;6:4

24. Akpabio E, Sagwa E, Mazibuko G, Kagoya H, Niaz Q, Mbalizi D. Assessment of Compliance of Outpatient Prescribing with the Namibia Standard Treatment Guidelines in Public Sector Health Facilities. Windhoek. Available from URL:

http://apps.who.int/medicinedocs/documents/s21715en/s21715en.pdf

25. Ministry of Health and Social Services. National Pharmacy Management Information Systems

(PMIS) Feedback report Apr - Sep 2015. Windhoek.

26. Pereko DD, Lubbe MS, Essack SY. Antibiotic use in Namibia: Prescriber practices for common community infections. South African Family Practice 2015;57(4): 231-235.

https://doi.org/10.1080/20786190.2015.1024021

27. Bronzwaer SL, Cars O, Buchholz U, Mölstad S, Goettsch W, Veldhuijzen IK et al. A European study on the relationship between antimicrobial use and antimicrobial resistance. Emerg Infect Dis. 2002;8(3):278-82.

28. Goossens H, Ferech M, Vander Stichele R, Elseviers M; ESAC Project Group. Outpatient antibiotic use in Europe and association with resistance: A cross-national database study. Lancet. 2005;365(9459):579-87.

29. Gyssens I. Antibiotic Policy. International Journal of Antimicrobial Agents. 2011;38S, 11-20.

30. Linder JA, Stafford RS. Antibiotic Treatment of Adults by Community Primary Care Physicians: National Survey, 1989-1999. JAMA. 2001;286(10):1181-6.

31. Mazur E. Rational antibiotic therapy of acute upper respiratory tract infections. Polski Merkuriusz Lekarski. 2010; 29(173), 304-308.

32. Riedel S, Beekmann SE, Heilmann KP, Richter SS, Garcia-de-Lomas J, Ferech M et al.

Antimicrobial use in Europe and antimicrobial resistance in Streptococcus pneumoniae. Eur J Clin

Microbiol Infect Dis. 2007;26(7):485-90.

33. Sumpradit N, Chongtrakul P, Anuwong K, Pumtong S, Kongsomboon K, Butdeemee P etal.

Antibiotics Smart Use: a workable model for promoting the rational use of medicines in Thailand. Bull World Health Organ. 2012;90(12):905-13

34. Llor C, Bjerrum L. Antimicrobial resistance: risk associated with antibiotic overuse and initiatives to reduce the problem. Therapeutic advances in drug safety. 2014;5(6):229-4

35. Fleming-Dutra KE, Hersh AL, Shapiro DJ, Bartoces M, Enns EA, File TM, Jr., et al. Prevalence of Inappropriate Antibiotic Prescriptions Among US Ambulatory Care Visits, 2010-2011. JAMA.

2016;315(17):1864-73

36. Adorka M, Honoré MK, Lubbe M, Serfontein J, Allen K. The impact of appropriate antibiotic prescribing on treatment evaluation parameters. Journal of Public Health in Africa. 2013; 4(1), 2 
37. Al-Niemat SI, Bloukh DT, Al-Harasis MD, Al-Fanek AF, Salah RK. Drug use evaluation of antibiotics prescribed in a Jordanian hospital outpatient and emergency clinics using WHO prescribing indicators. Saudi Med J. 2008;29(5):743-8.

38. Butler CC, Hood K, Verheij T, Little P, Melbye H, Nuttall J, et al. Variation in antibiotic prescribing and its impact on recovery in patients with acute cough in primary care: prospective study in 13 countries. BMJ. 2009;338:b2242

39. Osatakul S, Puetpaiboon A. Appropriate use of antibiotics in acute diarrhoae: a cross sectional survey in southern Thailand. Ann Trop Paediatr. 2007;27(2):115-22.

40. Akkerman AE, van der Wouden JC, Kuyvenhoven MM, Dieleman JP, Verheij TJ. Antibiotic prescribing for respiratory tract infections in Dutch primary care in relation to patient age and clinical entities. The Journal of antimicrobial chemotherapy. 2004;54(6):1116-21

41 Petersen I, Johnson AM, Islam A, Duckworth G, Livermore DM, Hayward AC. Protective effect of antibiotics against serious complications of common respiratory tract infections: retrospective cohort study with the UK General Practice Research Database. BMJ. 2007;335(7627):982

42. Kumar S, Little P, Britten N. Why do general practitioners prescribe antibiotics for sore throat? Grounded theory interview study. BMJ . 2003;326(7381):138.

43. Adriaenssens N, Coenen S, Tonkin-Crine S, Verheij TJ, Little P, Goossens H. European Surveillance of Antimicrobial Consumption (ESAC): disease-specific quality indicators for outpatient antibiotic prescribing. BMJ quality \& safety. 2011

44. Kunda M. An investigation of antibiotic prescribing in patients with upper respiratory tract infections (URTIs) at Katutura Health Centre. University of Namibia. Available from URL: http://repository.unam.na/handle/11070/843

45. Ministry of Health and Social Services. Namibia Standard Treatment Guidelines (1st ed.). Windhoek. Available from URL: http://apps.who.int/medicinedocs/documents/s19260en/s19260en.pdf 46. Matowe L, Waako P, Adome RO, Kibwage I, Minzi O, Bienvenu E. A strategy to improve skills in pharmaceutical supply management in East Africa: the regional technical resource collaboration for pharmaceutical management. Human resources for health. 2008;6:30

47. Waako PJ, Odoi-adome R, Obua C, Owino E, Tumwikirize W, Ogwal-Okeng J, et al. Existing capacity to manage pharmaceuticals and related commodities in East Africa: an assessment with specific reference to antiretroviral therapy. Human resources for health. 2009;7:21.

48. Teixeira Rodrigues A, Ferreira M, Pineiro-Lamas M, Falcao A, Figueiras A, Herdeiro MT.

Determinants of physician antibiotic prescribing behavior: a 3 year cohort study in Portugal. Current medical research and opinion. 2016;32(5):949-57

49. O'Keefe RM. Investigating Outpatient Departments: Implementable Policies and Qualitative Approaches. Journal of the Operational Research Society. 1985;36(8): 705-712.

https://doi.org/10.1057/jors.1985.12

50. Costelloe C, Metcalfe C, Lovering A, Mant D, Hay AD. Effect of antibiotic prescribing in primary care on antimicrobial resistance in individual patients: systematic review and meta-analysis. BMJ. 2010;340:c2096

51. Steinke DT, Bain DJ, MacDonald TM, Davey PG. Practice factors that influence antibiotic prescribing in general practice in Tayside. The Journal of antimicrobial chemotherapy.

2000;46(3):509-12

52. Ministry of Health and Social Services. Namibia Pharmaceutical Management Information System (PMIS) Manual. Windhoek.

53. Goossens H, Guillemot D, Ferech M, Schlemmer B, Costers M, van Breda M, et al. National campaigns to improve antibiotic use. European journal of clinical pharmacology. 2006;62(5):373-9 54. Drekonja DM, Filice GA, Greer N, Olson A, MacDonald R, Rutks I, et al. Antimicrobial stewardship in outpatient settings: a systematic review. Infection control and hospital epidemiology.

2015;36(2):142-52

55. World Health Organization. How to investigate drug use in health facilities: Selected drug use indicators. Available at URL: http://www.who.int/medicines/publications/how-to-investigate_druguse/en/

56. World Health Organization. Introduction to Drug Utilization Research World Health Organization WHO International Working Group for Drug Statistics Methodology. Available at URL: http://apps.who.int/medicinedocs/pdf/s4876e/s4876e.pdf

57. Ofori-Asenso R, Brhlikova P, Pollock AM. Prescribing indicators at primary health care centers within the WHO African region: a systematic analysis (1995-2015). BMC public health. 2016;16:724 58. Kallander K, Burgess DH, Qazi SA. Early identification and treatment of pneumonia: a call to action. The Lancet Global health. 2016;4(1):e12-3 
59. Williams BG, Gouws E, Boschi-Pinto C, Bryce J, Dye C. Estimates of world-wide distribution of child deaths from acute respiratory infections. The Lancet infectious diseases. 2002;2(1):25-32 60. World Health Organization. Namibia: WHO Statistical Profile. Available from URL: http://www.who.int/gho/countries/nam.pdf?ua=1

61. Adorka M, Mitonga HK, Allen K, Lubbe MS. Assessing the Effectiveness of Empiric Aantibiotic Treatments : The Use of an Antibiogram Based Methodology in the Case of Selected Public Hospitals in Lesotho. Journal of Pharmaceutical Care 2014; 2(3):85-95

62. Royal College of Pathologists. An audit of antimicrobial stewardship "Start Smart - then Focus" compliance with national and local recommendations for antimicrobial prescribing. Available from URL: https://www.rcpath.org/resourceLibrary/an-audit-of-antimicrobial-stewardship-start-smart-thenfocus-compliance-with-national-and-local-recommendations-for-antimicrobial-prescribing.html 63. Chowdhury AK, Khan OF, Matin MA, Begum K, Galib MA. Effect of standard treatment guidelines with or without prescription audit on prescribing for acute respiratory tract infection (ARI) and diarrhoea in some thana health complexes (THCs) of Bangladesh. Bangladesh Medical Research Council bulletin. 2007;33(1):21-30.

64. Kibuule D, Mubita M, Naikaku E, Kalemeera F, Godman BB, Sagwa E. An analysis of policies for cotrimoxazole, amoxicillin and azithromycin use in Namibia's public sector: Findings and therapeutic implications. International journal of clinical practice. 2017

65. Sabuncu E, David J, Bernede-Bauduin C, Pepin S, Leroy M, Boelle PY, et al. Significant reduction of antibiotic use in the community after a nationwide campaign in France, 2002-2007. PLoS medicine. 2009;6(6):e1000084

66. Furst J, Cizman M, Mrak J, Kos D, Campbell S, Coenen S, et al. The influence of a sustained multifaceted approach to improve antibiotic prescribing in Slovenia during the past decade: findings and implications. Expert review of anti-infective therapy. 2015;13(2):279-89

67. Godman B, Fadare J, Kibuule D, Irawati L, Mubita M, Ogunleye O, Paramadhas BDA et al. Initiatives across countries to reduce antibiotic utilization and resistance patterns; impact and implications. 2017; 539-576 in Drug Resistance in Bacteria, Fungi, Malaria, and Cancer - Arora, Sajid, \& Kalia Eds. Publisher Springer Nature. ISBN 978-3-319-48682-6. Available at URL: http://www.springer.com/us/book/9783319486826\# 